\title{
Problems of causation in world politics
}

Book

Accepted Version

Humphreys, A. R. C. and Suganami, H., eds. (2017) Problems of causation in world politics. Journal of International Relations and Development, 20 (4). Palgrave Macmillan. doi: https://doi.org/10.1057/jird.2016.14 Available at https://centaur.reading.ac.uk/62994/

It is advisable to refer to the publisher's version if you intend to cite from the work. See Guidance on citing.

To link to this article DOI: http://dx.doi.org/10.1057/jird.2016.14

Publisher: Palgrave Macmillan

All outputs in CentAUR are protected by Intellectual Property Rights law, including copyright law. Copyright and IPR is retained by the creators or other copyright holders. Terms and conditions for use of this material are defined in the End User Agreement.

\section{www.reading.ac.uk/centaur}

\section{CentAUR}

Central Archive at the University of Reading

Reading's research outputs online 


\section{Introduction: Problems of Causation in World Politics ${ }^{i}$}

What do the following questions have in common?

- Why do democracies not go to war with one another?

- What made the $19^{\text {th }}$-century Concert system more peaceful than its predecessor?

- How is democracy most effectively promoted?

- What impact does climate change have on migration?

One important feature they share is that in order to answer them we will need to advance causal claims about world politics." This indicates how tightly questions about causation are bound into the fabric of International Relations [IR]. Yet the point is not merely that these are causal questions, but also that how we think about causation and causal explanation will shape the kinds of answers we give and that those answers will, in turn, shape our understanding of the options open to policymakers and hence our judgements of their decisions. In other words, our stances on matters such as conflict prevention, democracy promotion and migration management are likely to be shaped by often tacit beliefs about the nature of causal processes and the extent to which they are amenable to human influence.

Recognizing this, we might turn to philosophy for guidance as to how to think about causation. If we do, we are liable to encounter a baffling range of positions (see Lebow 2014: 23-38). One that has proved highly influential within IR is Martin Hollis and Steve Smith's (1991: 1-7) distinction between two traditions of inquiry: a scientific, causal tradition which generates 'explanations' from the 'outside' and a hermeneutic or interpretive tradition which generates 'understanding' from the 'inside'. There are, however, several problems with this way of thinking about causal inquiry in IR. First, although they acknowledge the philosophical difficulties associated with it, Hollis and Smith's rendering of the causal tradition is strongly rooted in mid-twentieth-century positivism. Whereas they ask how applicable positivism is to the social sciences, it may be more pertinent to ask how adequate it is as an account of natural science (see Bhaskar 2008).iii Second, Hollis and Smith's (1991: 7) insistence that there are 'always two stories to tell', causal and non-causal, and that these cannot easily be combined reflects this highly restrictive understanding of the nature of causal explanation. Third, as Milja Kurki (2008: 5-6) notes, this taken-for-granted division between causal and non-causal approaches has worked to suppress debate about causation. Philosophers do not tend to dispute the meaning of the concept of causation, which denotes a form of natural necessitation or, in ordinary language, bringing about. They do, however, dispute (i) whether this concept of causation is merely an idea or rather corresponds to something real, (ii) the meaning of 
causal claims (for example, whether causal claims can and should be understood in counterfactual terms); (iii) how and to what extent we can generate knowledge of causal processes; and (iv) which methods, if any, are peculiarly appropriate for causal analysis.

Elements of these deeper philosophical disputes have, in recent years, made their way into IR, largely driven by the emergence of Critical Realism as a distinctive philosophical position within the discipline (see Wendt 1999; Patomäki and Wight 2000; Patomäki 2002; Wight 2006; Kurki 2008; Wight \& Joseph 2010). At the heart of the Critical Realist position is a critique of what Kurki (2008: 6) terms the 'Humean conception of causation', that is, the attempt to ground causal analysis in the identification of empirical regularities. This approach, Critical Realists argue, fails to take seriously the idea that the social world is predominantly an open system in which we cannot expect to find the kinds of regularities which scientists seek to isolate through experiment. Critical Realism provides a powerful alternative vision of a social world that is differentiated, layered and structured and in which underlying and unobservable causal powers and dispositions produce complex effects. Yet important questions remain about the extent to which philosophy can help us resolve problems of causation in world politics. Even if Critical Realists successfully expose the limitations of Humeanism, are their arguments equally successful against other forms of anti-realism (see Chernoff 2002; Lebow 2014)? If Patrick Jackson (2011) is right that a Critical Realist philosophical ontology should be understood as a wager on a par with that taken by neopositivists and others, then philosophy appears to open up multiple conflicting routes to answering the questions listed above.

One way in which recent philosophically-inspired discussion has, nonetheless, made a significant contribution is in questioning the widespread supposition that causal analysis is inimical to critical inquiry. As Kurki (2008: 124-44) shows, those critical IR theorists who have sought to distance their approaches from discussion of causality have really been rejecting a particular, Humean, form of causal analysis (see also Kurki and Suganami 2012). Yet it is crucial to recognize that this approach, and the methodological principles which accompany it (see, for example, King, Keohane and Verba 1994), does not exhaust all that can be said about causation in IR. It is perfectly possible to conduct causal analysis in a fashion which: is attentive to complexity and history; explains how and why patterns of behaviour and outcomes arise, rather than treating them as given; exposes the political effects of various forms of representation, including causal claims themselves; recognizes that reasons can be causes; and explores the conditions of possibility for particular outcomes as well as their efficient causes. In other words, if the language of causation, broadly understood, is hard to escape (see Kurki 2008: 16), then we should expect this to be reflected in the breadth of the causal 
questions we ask and the methods we use to answer them. Contrary to what is suggested by Hollis and Smith (1991), critical and interpretive questions and methods have an important place within causal inquiry.

This special issue therefore takes seriously much of the Critical Realist critique of the quasi-Humean approaches which dominate much of mainstream IR. The authors all broadly accept that the social world is an open system characterized by various forms of causal complexity and reject the overlydemanding expectations of causal analysis associated with the idea that we can discover causal laws and use them to make watertight predictions. We also take seriously the demand by critical scholars that insofar as we engage with problems of causation in world politics it is necessary to think not only in terms of efficient causes but also in terms of constraining and enabling conditions, including actors' reasons and the social structures which shape their understanding of the conditions of possibility they confront. We are also keenly aware that just as the ways in which we think about causation constrain and enable particular causal narratives, so causal claims themselves can have causal consequences insofar as they are internalized or acted on by policymakers (see, for example, Ish-Shalom 2013).

However, this special issue seeks to move beyond an increasingly entrenched debate between Critical Realists and their critics (see, for example, Wight 2007; Chernoff 2007) by exploring how the issues identified in those debates make their way into the broader discipline of IR and, beyond that, into world politics itself. Indeed, the contributors collectively identify at least five layers of analysis in how we think about causation in world politics:

1. Philosophical questions about what causation is, what we can know about it, and how, including the extent to which philosophy can answer such questions (see Suganami, this volume)

2. How causal claims are operationalized in causal explanations and what kinds of distinctive considerations emerge when we ask about the qualities of good causal explanations (see Jackson, Humphreys, this volume)

3. The extent to which causal thinking can be put to work to illuminate important dimensions of world politics (see Humphreys, Guzzini, Betts \& Pilath, this volume)

4. The impact of causal thinking in and on world politics (see Kurki, Betts \& Pilath, this volume)

5. Our capacity, through causal analysis, to think the future of world politics (see Patomäki, this volume) 
Explicitly identifying these five dimensions of how we think about causation in world politics highlights the fact that causal claims are not simply (according to our preferred criteria) right or wrong, better or worse evidenced, or more or less methodologically sound. Causal claims operate as interventions in the discipline of IR and, more broadly, in world politics. They are used by politicians, policymakers, academics, and ordinary citizens to satisfy curiosity, to resolve disputes, to justify actions (including, for example, the use of force), to counter criticism, to articulate and defend viewpoints, to allocate resources, and more. Confronting problems of causation in world politics therefore requires us to take seriously not only philosophical and methodological arguments about the proper nature of causal analysis, but also the many ways in which causal thinking shapes and is used to shape our world.

The special issue begins with a discussion by Hidemi Suganami of the common framing of debates about the nature of causation in the social world in terms of a dispute between Hume and Bhaskar. Noting various points at which the standard treatments of these authors can be misleading, Suganami sets the scene for the subsequent papers by identifying a little noticed agreement between Hume and Bhaskar over the idea that the empirical world is largely an open system, though one which may be characterized by local, partial closures in which causally-generated regularities are observable. This has important implications for our study of causal processes in IR. It means that the search for regularities is defensible but cannot be all that causal analysis involves: we also need to engage in more historically-oriented efforts to explain outcomes that cannot be subsumed under observable regularities. But Suganami also notes that at this point we reach the limits of what philosophy can offer to inquiries into problems of causation in world politics.

The next two contributions, by Patrick Jackson and Adam Humphreys, continue to engage with philosophy, but shift the focus away from the nature of causation to the nature of causal explanation. This is an oddly neglected topic in IR for, as both authors identify, explanations are partly pragmatic: they are human responses to particular problem situations. If we are interested in explaining particular aspects of world politics, as so many of us are, we need to think not only about how to identify causes, but also about how causal claims are operationalized in causal explanations.

Jackson argues that causal explanation should be understood not as involving the subsumption of particular instances under a general law, but as a practical-intentional activity which aims to give the recipient of the explanation a practical competence and understanding that they were previously lacking. Thus causal explanation is a different kind of activity from the formulation of mere causal 
claims. Because neopositivists mistakenly conflate the two, they also neglect to consider how their causal claims might be put to work in explanations which build practical competencies grounded in causal understandings. As with Suganami's contribution, Jackson's argument points towards the need to think of causal explanation in more historical terms, recognizing that the case-specific nature of causal explanation requires engagement not merely with regularities, but also with how multiple causal factors come together in case-specific configurations.

Humphreys highlights the implications of complexity for causal explanation. In world politics, most events we seek to explain have causal histories which are, to all intents and purposes, infinitely long and susceptible to infinitely detailed description. We therefore need to take seriously the oftenneglected question of what to focus on, for our choices will significantly shape the kinds of causal explanations we develop. Humphreys illustrates the significance of such choices in relation to debates between rationalist theorists and historians about what caused the relative peacefulness of the $19^{\text {th }}$-century Concert system. What emerges is that the rationalist approach is pragmatically adequate only on a very restrictive understanding of what it is that we are trying to explain. This, in turn, carries significant implications for the plausibility with which rationalists can trade on their ability to explain the peacefulness of the Concert system in offering policy prescriptions for the present.

Stefano Guzzini's contribution shows how important ideas about causation are for the study of world politics by exploring the difficulties that arise when power, one of IR's central concepts, is conceptualized as an efficient cause. He argues that power must be understood as relational, but that ultimately this requires us to embrace equifinality and non-linearity, which are incompatible with an understanding of power as an efficient cause. Pointing out the significant role that power plays in many approaches to world politics, Guzzini argues that it is the commonplace conceptualization of power as an efficient cause that must give way. He advocates conceiving of power in dispositional terms and argues that this exemplifies the broader case for conceiving of causation itself in dispositional terms. He illustrates what such a dispositional approach to causal analysis might look like by showing how causal mechanisms may be construed in dispositional terms, thereby allowing them to be put to use in interpretive analysis.

Moving beyond Guzzini's focus on the impact of causal thinking in the discipline of International Relations, Milja Kurki examines the impact of causal thinking in world politics. She does this by asking how Latour's concept of 'factish' can illuminate the role of causal thinking in democracy 
support. From a Latourian perspective, all causal thinking is an attempt to escape the realm of fetish, or belief, into a realm of fact, but this attempt can never be wholly successful. The value of this perspective, Kurki argues, is that it focuses our attention on what causal analysis does in the world. Whatever philosophical stance we might favour, the application of that stance produces a particular kind of lived reality. This is what Kurki explores in relation to democracy support. She argues that a full understanding of the role of causal thinking in democracy support activities must comprehend not only the presumptions about causal efficacy it embodies, but also the extent to which it contributes to the production of particular practices and understandings of democracy itself. Kurki thereby not only illustrates the substantive impact of causal thinking on international practices but also raises deep questions about what we can expect causal thinking to contribute to our attempts to shape world politics.

Alex Betts and Angela Pilath build on Kurki's interest in the impact of causal thinking on world politics by examining the political effects of causal claims linking environmental change to international migration. They note that although this is a highly complex area in which causal claims are at best contestable, some simplistic and even dubious causal claims have nonetheless made their way into key international agreements. To illustrate this, they explore the way in which causal claims around environmental migration were drawn upon in negotiations over the 2010 Cancún Adaptation Framework. They show that even poorly supported causal claims could be used by participants to confer legitimacy on their negotiating positions and that these political dynamics resulted in relatively unsupported causal claims being incorporated into the text of the agreement. They thereby demonstrate the need to think carefully about the political impact of causal reasoning and the conditions under which such reasoning should be granted a privileged status in political negotiations.

Patomäki concludes the special issue by asking to what extent it is possible for social scientists to predict or conceptualize the future of world politics. Neopositivist approaches to causal analysis treat explanation and prediction as symmetrical and hence countenance at least the possibility of accurate prediction. However, the key Critical Realist insight about the open systemic nature not only of the natural world but also, a fortiori, of the social world provides a strong reason to doubt that this is possible: even if local regularities are identified, they are liable to change as actors become aware of them and respond accordingly. However, Patomäki argues that our ability to operate in the world with some success shows that it is not radically contingent: even if prediction based on regularities is a fruitless endeavour, social scientific inquiry can help us to understand the 
causal structures which shape the possibilities open to us. This suggests the possibility, drawing on the Critical Realist vision of the world as a complex but structured reality, of engaging in a scenariobuilding exercise in which a certain, if limited, kind of futurology is possible.

Like Suganami, Jackson, Humphreys, and Guzzini, therefore, Patomäki is positive about our potential ability to grapple with problems of causation in world politics, even as he is sceptical of the utility of ingrained, neopositivist ways of thinking about causation. The appropriate response to the limitations of these standard ways of thinking is not to give up on causal analysis, but to embrace complexity. But like Kurki and Betts and Pilath, Patomäki is also aware of the need to explore the impact of causal thinking on the world. Just as we cannot escape problems of causation in world politics, so we cannot escape the fact that our collective responses to them will partly shape our futures. 


\section{Bibliography}

Bhaskar, Roy (2008) A Realist Theory of Science, London: Verso.

Chernoff, Fred (2002) 'Scientific Realism as a Meta-Theory of International Politics', International Studies Quarterly 46(2): 189-207.

Chernoff, Fred (2007) 'Critical Realism, Scientific Realism, and International Relations Theory', Millennium: Journal of International Studies 35(2): 399-407.

Hollis, Martin \& Smith, Steve (1991) Explaining and Understanding International Relations, Oxford: Clarendon Press.

Ish-Shalom, Piki (2013) Democratic Peace: A Political Biography, Ann Arbor: University of Michigan Press.

Jackson, Patrick T. (2011) The Conduct of Inquiry in International Relations: Philosophy of Science and its Implications for the Study of World Politics, London: Routledge.

King, Gary, Robert O. Keohane \& Sidney Verba (1994) Designing Social Inquiry: Scientific Inference in Qualitative Research, Princeton, New Jersey: Princeton University Press.

Kurki, Milja (2008) Causation in International Relations: Reclaiming Causal Analysis, Cambridge: Cambridge University Press.

Kurki, Milja \& Hidemi Suganami (2012) 'Towards the Politics of Causal Explanation: A Reply to the Critics of Causal Inquiries', International Theory 4(3): 400-29.

Lebow, Richard Ned (2014) Constructing Cause in International Relations, Cambridge: Cambridge University Press.

Patomäki, Heikki (2002) After International Relations: Critical Realism and the (Re)Construction of World Politics, London: Routledge.

Patomäki, Heikki \& Colin Wight (2000) 'After Postpositivism? The Promises of Critical Realism', International Studies Quarterly 44(2): 213-37.

Suganami, Hidemi (2013) 'Causation-in-the-world: A Contribution to Meta-Theory of IR', Millennium: Journal of International Studies 41(3): 623-43.

Van Fraassen, Bas C. (1980) The Scientific Image, Oxford: Clarendon Press.

Wendt, Alexander (1999) Social Theory of International Politics, Cambridge: Cambridge University Press.

Wight, Colin (2006) Agents, Structures and International Relations: Politics as Ontology, Cambridge: Cambridge University Press.

Wight, Colin (2007) 'A Manifesto for Scientific Realism in IR: Assuming the Can-Opener Won't Work!' Millennium: Journal of International Studies 35(2): 379-98. 
Wight, Colin \& Jonathan Joseph (eds.) (2010) Scientific Realism and International Relations, Basingstoke: Palgrave.

\footnotetext{
' I am grateful to Hidemi Suganami for comments on a previous draft of this introduction. The papers that constitute this special issue originated in a workshop held at the University of Reading in June 2014. The editors (Adam Humphreys and Hidemi Suganami) thank the Department of Politics and International Relations, the School of Politics, Economics and International Relations and the Faculty of Arts, Humanities and Social Sciences at the University of Reading for making that workshop possible. Several of the papers were also presented at the British International Studies Association's annual conference in Dublin, also in June 2014. We are grateful to participants at the workshop and conference for stimulating questions and comments, to the many anonymous reviewers for their careful reading of the papers, and especially to Annette Freyberg-Inan at the Journal of International Relations and Development for her encouragement and support and for shepherding the process patiently and effectively.

ii This is not to rule out the possibility that we will regard the questions as misleading in their current form and hence refuse the invitation to answer them.

iii The kinds of positivist arguments on which they draw have long-since been abandoned even by empiricist philosophers of science (see van Fraassen 1980).
} 